\title{
Comparing the Potentiality of Propane, Propanol and Octane Fuel Using in SI Engine Based on Energy-Exergy Analysis
}

\author{
Md Mizanuzzaman Mizan \\ Bangladesh Military Academy (BMA), Bhatiary, Bangladesh \\ email: mizan_zaman@yahoo.com
}

\section{ARTICLE INFO}

Article History:

Received: 28 ${ }^{\text {th }}$ August 2020

Revised: 23rd April 2021

Accepted: 25th April 2021

Published: 27th June 2021

Keywords:

Potentiality

Energy

Irreversibility

Exergy

Combustion

Friction

efficiency

\section{A B S T R A C T}

From the beginning of IC engine era, it is trying to improve the performance and efficiency of internal combustion engine. In this study, numerically analysis on combustion of Propane, Propanol and Octane in SI engine have been done thoroughly and presented to assess the potentiality and highlighted the comparison. For this analysis thermodynamic engine cycle model is developed for numerical analysis. Mathematical models considering fundamental equation and empirical relation are implemented in a single cylinder 4 stroke spark ignition engine (system) with the help of FORTRAN 95 to find out heat losses, friction losses, output parameter etc. Single cylinder four-stroke spark-ignition (SI) engine is considered as system. In this study, different working parameters like 8 and 12 compression ratios with three different rpm 2000, 4000 \& 6000 are considered for simulation. This study shows the different comparisons of energy-exergy content (\%), as example of exhaust gas 35.08 \& 17.82, 37.02 \& 19.22, $37.79 \& 19.79$ for Octane (at compression ratio 8 and 2000, 4000, 6000 rpm) etc., which explains the potentiality content and the potentiality losses in different process like combustion, mixing of gases etc. It also shows for the fuel propane and propanol in similar way with changing different operating conditions. Maximum inside cylinder temperature, 1st law and 2nd law efficiencies were determined for the fuels with respect to different compression ratio and engine speed.

(c) 2021 MIJST. All rights reserved.

\section{INTRODUCTION}

Nowadays it is a great concern about the energy conservation and its efficient uses. The reserve of fuels is reducing day by day so need to find out alternative source or efficient conversion techniques. Alternative fuels also known as 'cleaner fuel' is great concern in this regard. With better combustion technique alternative fuels burns efficiently and give less emission than conventional fuels (Moran \& Shapiro, 2000). Alternative fuels are inherently cleaner than petroleum derived fuels. Alternative fuels usually are less harmful to the environment and greater suitable than conventional fuels. By the using of advanced emission control technologies, it was found that the efficient burn of alternative fuels and less harmful ingredients released from incomplete combustion. Advanced combustion and emission control technology requires combustion data with certain degree of detailing. But for better combustion technique and conversion technology, it requires combustion data or properties for alternative fuel.
Generation of experimental data is very expensive, and therefore more emphasis is given, now-a-days, on modelled results for combustion of non-conventional fuels.

Propane normally is a gas at normal temperature and pressure (NTP) and becomes liquid (after compression) during transport. Propane uses as a fuel in different purposes. There is also a possibility to use as refrigerant in air conditioning system.

After diesel and petrol, the large amount of heat energy is produced by the complete combustion of propane. Also, propane is known as a cleaner fuel and produces lower emission to the environment. So as a result, the propane is becoming the third fuel after petrol and diesel to use as a vehicle fuel.

Comparing with the traditional fuel propane is an abundance of supply, can be stored at low pressure, offers good safety and low cost. Propanol considering as primary alcohol is less toxic and less volatile than propane. Propanol producing 
less amount of undesirable $\mathrm{CO}$ and unstable $\mathrm{HC}$ during combustion process than gasoline fuel (Eduardo \& Fernando, 2017).

The performance of an internal combustion engine has been ascertained by the calculated energy value with the help of the first law of thermodynamic. Energy cannot be destroyed but transformed one form to another. But now it was found first law of thermodynamic alone cannot explain the all phenomenon of combustion process accurately (Kumar et al., 2015). It cannot identify the actual potentiality of the fuel because of its limitations like not considering the energy losses due to irreversible process like combustion, heat transfer, mixing of gases etc. so with the help of 1st law of thermodynamics alone the potentiality losses due to different process/ sources cannot be identified, as a result it hinders the further improvement of the total process/ system. For this reason, the 2nd law of thermodynamics has been extensively used in the field of IC engines. During a process or a system analysis in terms of the 2nd law of thermodynamics is named exergy or availability analysis. Exergy analysis for IC engine system and process proves to be very convenient because it highlights the essential information about the irreversibility as well as exergy losses in the process or system. So, the thermodynamic efficiency can be measured, gray areas can be specified and thus processes or systems can be designed and functioned to be in efficient way (Moran \& Shapiro, 2000). So, exergy calculation based on 2nd law of thermodynamics considered in this study to overcome this issue. Exergy analysis is an appropriate tool for scientists and academics to investigate the thermodynamic processes and systems. The 2nd law of thermodynamics states that energy has quality and quantity as well. By introducing exergy, it provides an alternative mean of evaluating and comparing processes and systems realistically. Again, the various thermodynamics data for alternative fuels like propane and propanol is not available in various operating conditions of SI engine. So, considering all the issues the present study highlighted the potentiality as well as the sources of potentiality losses including different thermodynamic data for propane, propanol, and octane fuel during the combustion in SI engine.

Exergy is explained the maximum theoretical work as when a system with specific process comes to the equilibrium condition with the reference environment. System and process contain the amount of exergy depends on the degree of systems quality or possible system utility, its capability to execute work. Nowadays the exergy calculation technique became commonly used in the estimation, calculation, design, model and performance calculation of thermodynamic process and system.

As the exergy of a system contain fuel is diminished during irreversible processes, the total fuel energy cannot be transformed to useful work even during complete combustion. In view of this exergy destruction, exergetic efficiency offers more realistic measures for calculating the effectiveness of the energy conversion system during combustion.
Based on exergy analysis produces an exact amount of real performance styles the perfect, and undoubtedly indicates the reasons and the sources of systems potentiality reduces. Exergy calculation can contribute in refining and improving design (Hakan, et. al., 2018 \& Juan, et. al. 2018). However, potentiality of propane, propanol and octane fuel in SI engine is still in research investigation, in particular, in terms of energy-exergy analysis. Therefore, exergy analysis technique is applied in this process like compression, combustion, and expansion phases of spark ignition engine.

\section{METHODOLOGY}

FORTRAN 95 programming language is used as a based program to write the simulation software considering all the necessary governing equation. Module wise programming for different process like compression, combustion, expansion, heat transfer, friction etc. has been done to calculate the various results due to different engine conditions. Key parameters and boundary conditions are also shown in Table 1 and 2.

In this study, a two-zone thermodynamic-based combustion model was developed for Energy - Exergy analysis of internal combustion engine (SI). By using FORTRAN 95 the governing equations with boundary conditions are numerically solved considering 0.1 degree CA as unit time step. After the power stroke the estimation for a process in a cycle stops when the exhaust valve opens and $P_{\mathrm{e}}$ and $T_{\mathrm{e}}$ are noted to compute the temperature at the beginning of the cycle, $T_{\mathrm{IVC}}$ and residual gas fraction, $f$. The computation process is repeated with assessed values of residual mass fraction and temperature at inlet valve closed until converged solution is attained.

\section{A. Basic Equations of SI Engine Cycle}

The cylinder volume is the function of crank angle $(\theta)$. The governing equation (1) of volume is as follows (Ferguson \& Kirkpatrick, 2001):

$V(\theta)=\frac{V_{D}}{R_{C}-1}+\frac{V_{D}}{2}\left[\left(\frac{2 L_{C}}{L_{S}}\right)+1-\cos \theta-\sqrt{\left(\frac{2 L_{C}}{L_{S}}\right)^{2}-\sin ^{2} \theta}\right]$

where, the displacement volume can be expressed as $V_{D}=$ $\frac{\pi}{4} B^{2} L_{S}$, where, $B, L_{S}, R_{c}$ and $L_{\mathrm{c}}$ are bore, stroke length, compression ratio and connecting rod length, respectively.

The infinitesimal change of pressure in cylinder, $d p$ can be explained by Eq. (2) (Ferguson \& Kirkpatrick, 2001):

$d P(\theta)=-K P(\theta)\left[\frac{d V(\theta)}{V(\theta)}\right]+(k-1)\left[\frac{\delta Q_{n e t}(\theta)}{V(\theta)}\right]$

where, the specific ratio, $k=C_{p} / C_{v}$ and $\delta Q_{n e t}(\theta)=$ $\delta Q_{\text {fuel }}-\delta Q_{\text {loss }}(\theta)$.

From the 1st law of thermodynamics, it is noted that

$\delta Q_{\text {net }}(\theta)=d U(\theta)+\delta w(\theta)$

where, $\delta w=P d V$ and $d U=m C_{v} d T$ assuming $P V=$ $m R T$ for ideal gas.

The reference data used in this study is stated in Table 1 (Rakopoulos, 1993). 
Table 1

Engine specification (Haq \& Morshed, 2013; Rakopoulos, 1993)

\begin{tabular}{cccccc}
\hline \hline Bore dia & Stroke length & Connecting rod length & Start of Combustion & Combustion duration & Compression ratio \\
\hline $76.3 \mathrm{~mm}$ & $111.1 \mathrm{~mm}$ & $160.0 \mathrm{~mm}$ & $330^{\circ}$ & $60^{\circ}$ & 7 \\
\hline \hline
\end{tabular}

\section{B. Wiebe Function as Fuel Burn Profile}

Considering the ideal spark ignition engine cycle, air-fuel mixture inside the cylinder never burns instantly rather it requires some time and follows a profile or curve which can be explained by the Wiebe function (Heywood, 1988):

$y_{b}(\theta)= \begin{cases}1-\exp \left[-a\left(\theta-\theta_{s} / \Delta \theta_{b}\right)^{b}\right] & \text { if } \theta_{s} \leq \theta \leq \theta_{s}+\Delta \theta_{b} \\ 0 & \text { if } \theta<\theta_{s}, \theta>\theta_{s}+\Delta \theta_{b}\end{cases}$

where, $y_{b}(\theta)$ is the burnt mass fraction at a CA, $\theta$ is the combustion start (CA), $\Delta \theta_{b}$ is the duration of combustion, $a$ is Wiebe efficiency factor and $b$ is Wiebe form factor.

\section{Energy Analysis}

Total heat release from the air-fuel mixture combustion, $\delta Q_{f u e l}$ can be written as:

$$
\delta Q_{f u e l}(\theta)=Q_{L H V} \cdot y_{s} \cdot d y_{b} \cdot(1-f)
$$

where,

$y_{S}=\frac{(F / A)_{S}}{(F / A)_{S}+1}$

The heat losses from the gases to the cylinder walls, $\delta Q_{\text {loss }}$, can be determined with a Newtonian convection Eq (7):

$$
\delta Q_{\text {loss }}(\theta)=h_{g}(\theta) \cdot A_{w}(\theta) \cdot\left[T(\theta)-T_{w}\right] \cdot \frac{d \theta}{2 \pi N}
$$

Cylinder area $A_{w}(\theta)$ is sum of the cylinder wall, cylinder head and piston head area expressed as:

$$
\begin{aligned}
& A_{w}(\theta)=A_{\text {wall }}+A_{\text {head }}+A_{\text {piston }} \\
& =2 V_{D}\left[\frac{1}{L_{s}}+\frac{1}{B}\left\{\left(\frac{2 L_{c}}{L_{s}}\right)+1-\cos \theta-\sqrt{\left(2 L_{c} / L_{s}\right)^{2}-\sin ^{2} \theta}\right\}\right]
\end{aligned}
$$

The instantaneous heat transfer coefficient, $h_{g}(\theta)$ can be determined by Woschni correlation (Ferguson \& Kirkpatrick, 2001) as:

$$
h_{g}(\theta)=3.26[P(\theta)]^{0.8} \cdot\left[U_{g}(\theta)\right]^{0.8} \cdot B^{-0.2} \cdot[T(\theta)]^{-0.55}
$$

where, $U_{g}$ is the characteristic gas velocity and proportional to mean piston speed during different process of cycle. When pressure rises during combustion then gas velocities also increase. As a result, value of $U_{g}$ is calculated by mean piston speed, $\bar{U}_{p}=2 N L_{s}$ \& cylinder pressure, $\left(P-P_{m}\right)$. Hence,

$U(\theta)=2.28 \bar{U}_{p}+0.00324 T_{0}\left[\frac{V(\theta)}{V_{D}}\right]\left[\frac{P(\theta)-P_{m}(\theta)}{P_{0}}\right]$

where, motoring pressure $P_{m}$ is obtained by using the motor for movement of the piston considering without combustion or heat release and its value is calculated as: (Stone, 1999):
$P_{m}(\theta)=P_{0}\left[\frac{V_{0}}{V(\theta)}\right]^{1.3}$

For the clearance volume of inside cylinder there must be some residual exhaust remained after the exhaust stroke. Fresh air-fuel mixture mixed with this left residual exhaust. As a result, temperature of the air-fuel mixture increases and volumetric efficiency decreases. The residual gas fraction, $f$, is defined as the ratio of the mass after exhaust stroke (residual gas mass) and the mass when the piston at bdc after the intake stroke. The residual gas fraction, $f$, can be calculated as (Ferguson \& Kirkpatrick, 2001):

$f=\frac{1}{R_{C}}\left[\frac{P_{e}}{P_{E V C}}\right]^{\frac{1}{k}}$

For unthrottled engine, considering $P_{\mathrm{e}}=$ atmospheric pressure. Hence, temperature at the beginning of the cycle, $T_{\text {IVC }}$ is correlated with the residual gas fraction, $f$ can be calculated as (Ferguson \& Kirkpatrick, 2001):

$T_{I V C}=(1-f) \cdot T_{i}+f \cdot T_{e} \cdot\left[1-\left(1-\frac{P_{i}}{P_{e}}\right)\left(\frac{k-1}{k}\right)\right]$

Now the efficiency of the cycle is defined to compare different engine and estimate different improvements effects from the perspective of either the first or the second law of thermodynamics (Rakopoulos, 1993; 2006). The 1st law efficiency which is energy-based is defined as (Sezer \& Bilgin, 2008; Mizanuzzaman, 2017):

$$
\begin{aligned}
& \eta_{I, \text { ind }}=\frac{\text { Energy out }\left(\text { as Indicated work, }, W_{\text {ind }}\right)}{\text { Energy in }\left(m_{f} Q_{L H V}\right)} \text { or } \\
& \eta_{I, b r k}=\frac{\text { Brake work, } W_{\text {brk }}}{m_{f} Q_{L H V}}
\end{aligned}
$$

In this study, brake thermal efficiency is used as 1st law efficiency.

\section{Equilibrium Chemical Composition and Thermodynamic Properties}

In this analysis, the chemical formula of fuel is considered as $C_{\alpha} H_{\beta} O_{\gamma} N_{\delta}$. Actual reaction of air (atmospheric condition) and fuel at equilibrium condition by volume is shown as (Ferguson \& Kirkpatrick, 2001):

$$
\begin{aligned}
& \epsilon \overbrace{\mathrm{C}_{\alpha} \mathrm{H}_{\beta} \mathrm{O}_{\gamma} N_{\delta}}^{\text {fuel }}+\overbrace{0.21 O_{2}+0.79 N_{2}}^{\text {air }} \\
& =v_{1} \mathrm{~N}_{2}+v_{2} \mathrm{O}_{2}+v_{3} \mathrm{CO}+v_{4} \mathrm{H}_{2}+v_{5} \mathrm{CO}_{2}+v_{6} \mathrm{H}_{2} \mathrm{O}+v_{7} \mathrm{H}+ \\
& v_{8} \mathrm{O}+v_{9} \mathrm{NO}+v_{10} \mathrm{OH}
\end{aligned}
$$

The coefficients $v_{i}(i=1,2,3 \ldots)$ that describes the product composition, $\epsilon$ is the molar fuel-air ratio and can be calculated by $\epsilon=0.21 /(\alpha+0.25 \beta-0.5 \gamma)$. By using atom balance and equilibrium constant, number of mole numbers and mole fraction of 10 specified products can be estimated. NASA polynomials are also used to find out the specific heat ratio and Gibbs free energy. Then all other 
thermodynamic properties like entropy, enthalpy, internal energy etc. can be estimated easily.

\section{E. Exergy Analysis}

Exergy in a system or total exergy can be divided into two parts such as thermomechanical exergy and chemical exergy (Wark, 1995). Hereafter,

$E X_{t o t}=E X_{t m}+E X_{c h}$

When a system goes through reversible process to reach the environment state ( $\mathrm{P} 0, \mathrm{~T} 0)$, then the work obtained from the system \& environment is called the thermomechanical exergy. This is the condition of restricted dead state condition. Here mixing and chemical reaction of the composition of system \& environment was not considered. In this restricted dead state condition, there is a scope to mixing and chemical reaction of the composition of system and the environment. If this chemical reaction occurs through reversible process, then additional work obtained from the system and environment is called as chemical exergy. And at equilibrium condition this is called unrestricted dead state condition (Kuntesh, et. al., 2017).

Thermomechanical and chemical exergy can be defined as (Wark 1995):

$$
\begin{aligned}
& E X_{t m}=u+P_{0} v-T_{0} s-\sum_{i=1}^{n} y_{i} \mu_{i, 0} \\
& E X_{c h}=\sum_{i=1}^{n} y_{i}\left(\mu_{i, 0}-\mu_{i, 00}\right)
\end{aligned}
$$

Here $\mu_{i, 0}$ is defined as the chemical potential of $i$ species at restricted dead state condition and $\mu_{i, 00}$ is defined as the chemical potential of $i$ species at unrestricted dead state condition.

The chemical exergy in a system can be divided as the following equations:

$$
\begin{aligned}
E X_{\text {ch }} & =E X_{\text {diffusion }}+E X_{\text {reactive }} \\
& =E X_{\text {diffusion }}+E X_{\text {oxidation }}+E X_{\text {reduction }}
\end{aligned}
$$

Normally exergy in a system like internal combustion engine (SI) uses or losses as work, heat transfer, exhaust gas from cylinder and destructed causes of combustion of air-fuel mixture (irreversibility). Here equations (19-21) show the fuel exergy and exergy uses as work and loses as heat transfer:

Fuel exergy:

$E X_{\text {fuel }}=-(\Delta g)_{T_{0}, P_{0}}$

Exergy transfer as work:

$E X_{w}=\int \delta w=\int P d v$

Exergy transfer as heat:

$E X_{Q}=\int\left(1-T_{0} / T\right) \delta q$
In the present study the following definition is used for second law efficiency (Sezer \& Bilgin, 2009; Mizanuzzaman, 2018):

$$
\begin{aligned}
\eta_{I I} & =\frac{\text { Exergy out (as work })}{\text { Maximum extractable exergy (as work })} \\
& =\frac{W_{\text {ind }}}{W_{\max }}=\frac{W_{\text {ind }}}{W_{\text {ind }}+I}
\end{aligned}
$$

With the above discussion it can be concluded that the second law efficiency provides a better thoughtful of performance than the first law efficiency. Moreover, the second law efficiency stresses both exergy losses due to the dealing with irreversibility to improve performance.

\section{F. Friction Calculation}

For estimating the efficiency of a Spark Ignition engine, friction calculation is one of the requirements. Friction is a totally irreversible process. It will reduce the exergy of a system as well as the potentiality to do the work. There are several ways to calculate the friction. All governing equation and calculation described in ref (Bishop, 1964; Mizanuzzaman, 2012; Mizanuzzaman, 2013), the total friction is occurred in various parts in SI engine, that is:

Total Friction Loss $=$ Friction losses in ( piston + valve train + crank shaft + pumping + accessory)

\section{RESULTS AND DISCUSSION}

Energy and exergy analysis together gives a better result regarding the performance of a system. Recently exergy analysis became popular and essential tools for simulation and performance analysis of an internal combustion engine (SI).

The energy-exergy distribution for stoichiometric propane, propanol and octane fueling with efficiency in different processes of spark ignition engine at three different speeds have been shown in Figures $1 \& 2$. Furthermore, maximum inside cylinder temperature has been shown in Figure 3. Energy balance calculation does not consider the exergy losses due to irreversibility and degradation of its quality. But this irreversibility can play an important role in further performance improvement design.

Engine speed variations have been given few important observations. Heat transfer from the cylinder becomes less due to less time for it by increasing engine speed. So, at higher engine speed the remaining energy makes the exhaust temperature increasing because of higher loss of exhaust energy. Again, at higher engine speed provides lower heat transfer exergy losses and higher exhaust exergy to atmosphere. Few important parameters like adiabatic temperature, $L H V$, maximum temperature \& pressure of three fuels are also validated (Haq \& Morshed, 2013; Simeon \& Kiril, 2012). However, work done, and work potential are comparable in various speeds and compression ratio shown in Table 2. 
Table 2

Energy-Exergy Distribution (\%)

\begin{tabular}{|c|c|c|c|c|c|c|c|c|c|c|c|c|c|c|}
\hline Fuel & $\mathbf{R}_{\mathbf{c}}$ & rpm & $\begin{array}{c}\text { Energy } \\
\text { work }\end{array}$ & $\begin{array}{c}\text { Energy } \\
\text { heat }\end{array}$ & $\begin{array}{l}\text { Energy } \\
\text { exhaust }\end{array}$ & $\begin{array}{l}\text { Energy } \\
\text { friction }\end{array}$ & $\begin{array}{l}\text { Energy } \\
\text { unaval }\end{array}$ & $\begin{array}{c}\text { 1st } \\
\text { law } \eta\end{array}$ & $\begin{array}{c}\text { Exergy } \\
\text { work }\end{array}$ & $\begin{array}{c}\text { Exergy } \\
\text { heat }\end{array}$ & $\begin{array}{c}\text { Exergy } \\
\text { exhaust }\end{array}$ & $\begin{array}{l}\text { Exergy } \\
\text { friction }\end{array}$ & $\begin{array}{l}\text { Exergy } \\
\text { unaval }\end{array}$ & $\begin{array}{l}\text { 2nd } \\
\text { law } \eta\end{array}$ \\
\hline \multirow{6}{*}{$\mathrm{C}_{3} \mathrm{H}_{8}$} & \multirow{3}{*}{8} & 2000 & 36.56 & 16.01 & 35.08 & 3.66 & 8.70 & 36.56 & 36.03 & 13.37 & 17.82 & 3.61 & 29.18 & 57.59 \\
\hline & & 4000 & 37.69 & 11.84 & 37.02 & 5.99 & 7.47 & 37.69 & 37.14 & 9.90 & 19.22 & 5.90 & 27.84 & 60.72 \\
\hline & & 6000 & 38.11 & 10.20 & 37.79 & 9.20 & 4.70 & 38.11 & 37.55 & 8.53 & 19.79 & 9.06 & 25.07 & 65.03 \\
\hline & \multirow{3}{*}{12} & 2000 & 39.12 & 19.32 & 30.08 & 4.13 & 7.36 & 39.12 & 38.55 & 16.01 & 14.40 & 4.07 & 26.97 & 61.24 \\
\hline & & 4000 & 41.00 & 13.92 & 32.38 & 6.43 & 6.27 & 41.00 & 40.41 & 11.55 & 16.00 & 6.34 & 25.70 & 64.52 \\
\hline & & 6000 & 41.71 & 11.81 & 33.30 & 9.69 & 3.50 & 41.71 & 41.10 & 9.80 & 16.65 & 9.55 & 22.90 & 68.86 \\
\hline \multirow{6}{*}{$\mathrm{C}_{3} \mathrm{H}_{8} \mathrm{O}$} & \multirow{3}{*}{8} & 2000 & 35.88 & 15.32 & 34.22 & 3.54 & 11.05 & 35.88 & 35.04 & 12.63 & 17.01 & 3.46 & 31.87 & 54.71 \\
\hline & & 4000 & 36.95 & 11.31 & 36.08 & 5.79 & 9.88 & 36.95 & 36.08 & 9.34 & 18.33 & 5.65 & 30.60 & 57.70 \\
\hline & & 6000 & 37.34 & 9.74 & 36.93 & 8.89 & 7.20 & 37.34 & 36.47 & 8.04 & 18.86 & 8.69 & 27.94 & 61.78 \\
\hline & \multirow{3}{*}{12} & 2000 & 38.47 & 18.45 & 29.34 & 3.99 & 9.75 & 38.47 & 37.57 & 15.10 & 13.73 & 3.90 & 29.70 & 58.27 \\
\hline & & 4000 & 40.25 & 13.27 & 31.54 & 6.22 & 8.71 & 40.25 & 39.31 & 10.87 & 15.24 & 6.07 & 28.51 & 61.42 \\
\hline & & 6000 & 40.92 & 11.25 & 32.42 & 9.37 & 6.04 & 40.92 & 39.96 & 9.21 & 15.84 & 9.15 & 25.83 & 65.53 \\
\hline \multirow{6}{*}{$\mathrm{C}_{8} \mathrm{H}_{18}$} & \multirow{3}{*}{8} & 2000 & 35.95 & 15.44 & 34.01 & 3.55 & 11.05 & 35.95 & 35.08 & 12.74 & 16.95 & 3.46 & 31.77 & 54.81 \\
\hline & & 4000 & 37.04 & 11.40 & 35.88 & 5.80 & 9.87 & 37.04 & 36.14 & 9.42 & 18.27 & 5.66 & 30.50 & 57.81 \\
\hline & & 6000 & 37.44 & 9.81 & 36.63 & 8.92 & 7.20 & 37.44 & 36.53 & 8.11 & 18.81 & 8.70 & 27.85 & 61.90 \\
\hline & \multirow{3}{*}{12} & 2000 & 38.51 & 18.59 & 29.14 & 4.00 & 9.76 & 38.51 & 37.58 & 15.22 & 13.67 & 3.91 & 29.63 & 58.34 \\
\hline & & 4000 & 40.32 & 13.37 & 31.35 & 6.23 & 8.73 & 40.32 & 39.34 & 10.96 & 15.18 & 6.08 & 28.44 & 61.50 \\
\hline & & 6000 & 40.99 & 11.33 & 32.23 & 9.40 & 6.05 & 40.99 & 40.00 & 9.29 & 15.79 & 9.17 & 25.76 & 65.62 \\
\hline
\end{tabular}

Figure 1 shows the amount of energy and exergy in different process for propane is a little different than other fuels. Because of modest molecular structure and better mixing and combustion propane air mixture combustion produced a bit less generation of irreversibility. At present study, due to high combustion temperatures, maximum exergy contained in fuel is lost due to transfer of heat and as exhaust gases. Considering octane and propanol, propane showed moderately better results as of lower exergy loss (exergy unavailable) with irreversibility and higher work exergy. Work exergy and heat transfer for propanol were similar trend of conventional octane fuel. Few important observations by using three different fuels such as propane, propanol and octane are as follows:

At $2000 \mathrm{rpm}$, fuel energy of 35.88 to $36.56 \%$ is converted to useful work, and at $6000 \mathrm{rpm}$ the energy percentages of 37.34 to $38.11 \%$ is converted to useful work at compression ratio 8 .

At $2000 \mathrm{rpm}$, fuel energy losses are 15.32 to $16.01 \%$ and 9.74 to $10.20 \%$ at $6000 \mathrm{rpm}$, respectively due to heat transfer. On the other hand, at $6000 \mathrm{rpm}$, associated fuel exergy losses are 8.04 to $8.53 \%$ and 12.63 to $13.37 \%$ at $2000 \mathrm{rpm}$, respectively at compression ratio 8 .

At $2000 \mathrm{rpm}$, fuel energy of 34.01 to $35.08 \%$ is lost with exhaust gases, whereas, at $6000 \mathrm{rpm}, 36.63$ to $37.79 \%$ losses are found. Similarly, exergy losses are found as 16.95 to $17.82 \%$ at $2000 \mathrm{rpm}$ and 18.81 to $19.79 \%$ at 6000 rpm, respectively with exhaust gases at compression ratio 8 .

Energy losses are found as 3.54 to $3.66 \%$ due to friction at $2000 \mathrm{rpm}$ and 8.89 to $9.2 \%$ at $6000 \mathrm{rpm}$, respectively at compression ratio 8 . It is noted that exergy losses with friction are nearly same as energy losses. However, fuel exergy is demolished of 29.18 to $31.87 \%$ at $2000 \mathrm{rpm}$ because of irreversibility and 25.07 to $27.94 \%$ at $6000 \mathrm{rpm}$ when compression ratio is 8 .

It is found that as engine speed increases, the work output, energy/exergy exhaust loss and friction loss are increased. But at the same time losses for heat transfer and irreversibility's (when considering exergy of fuel) are decreased. 

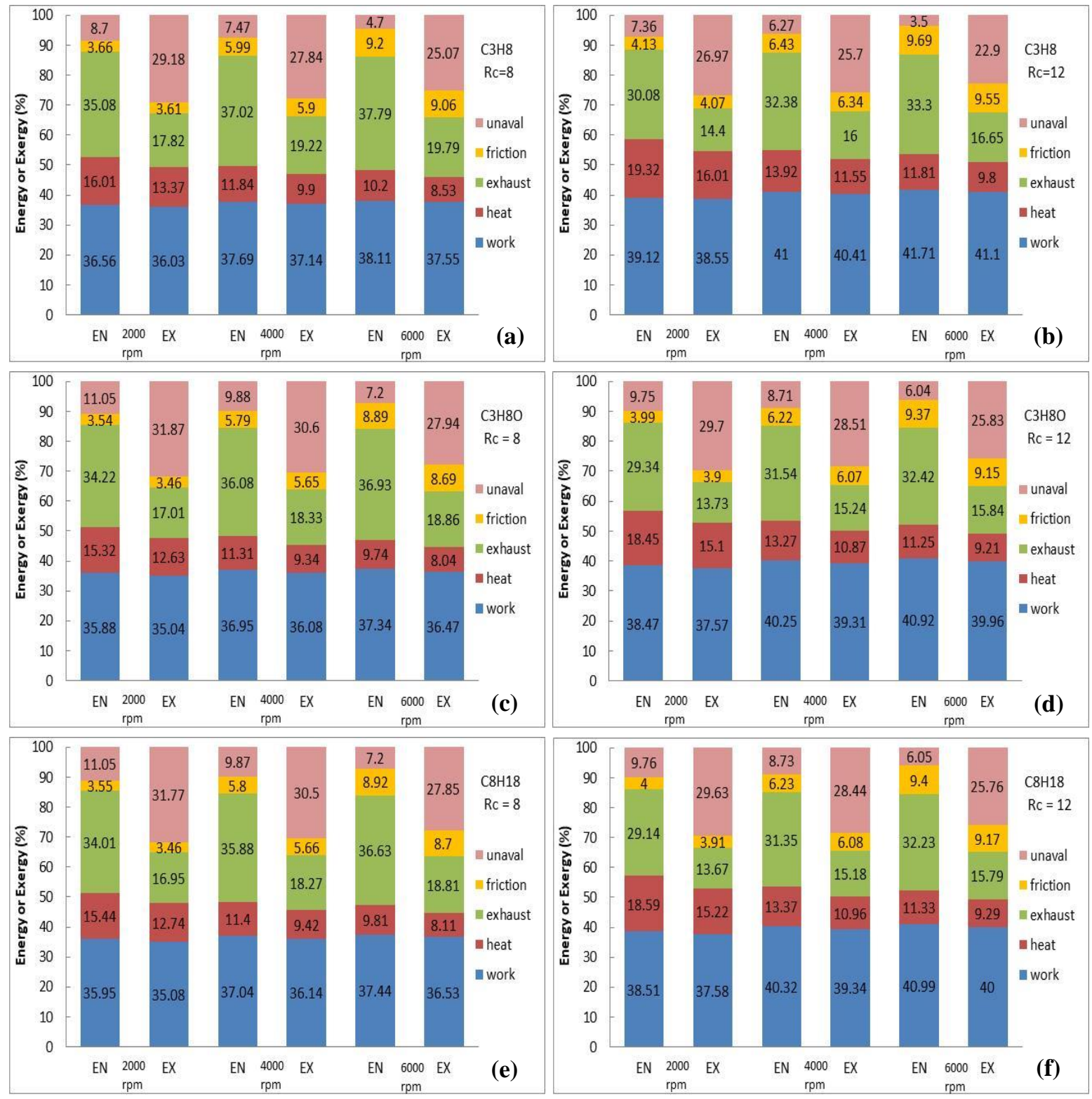

Figure 1: Energy and Exergy distribution for Propane, Propanol and Octane (stoichiometric condition) at different rpm and compression ratios, (a) C3H8, Rc=8; (b) C3H8, Rc=12; (c) C3H80, Rc=8; (d) C3H80, Rc=12; (e) C8H18, Rc=8; (f) C8H18, Rc=12

Figure 2 indicates the $1^{\text {st }}$ and $2^{\text {nd }}$ law efficiencies, depending on compression ratio and $\mathrm{rpm}$. Trend of $1^{\text {st }}$ and $2^{\text {nd }}$ law efficiencies are usual and similar trend for compression ratio and rpm. It is found that 1 st law efficiency for propane is slightly greater than other two fuels with various engine rpm and compression ratios. 1st law efficiency for octane and propanol is nearly same for different engine speed and compression ratios. 1st law efficiency found increased for all the fuels while increasing engine speed and compression ratios. For similar trend of first law efficiency, second law efficiency also found increased for all fuels while increasing engine speed and compression ratio. Propanol and octane show the similar trend and value for second law efficiency. Figure 3 shows the comparison of maximum inside cylinder temperature at different rpm and compression ratios. It was found that maximum temperature increases with increasing rpm but decreasing when compression ration increases. For propane, total irreversibility (friction plus unavailable exergy) is minimum or less than other two fuels and this value also increase with rpm but slightly decrease with compression ratio. There is a more scope to reduce the total irreversibility and so to increase the performance for propanol and octane. Normally compression ration increases the potentiality of the gases or liquid used in SI engine, at the same time it also increases the $1^{\text {st }}$ law and the $2^{\text {nd }}$ law of thermodynamics. In this study it was found that the potentiality of propane is greater than the octane and propanol. It is also found that with considering the concept of irreversibility, the potentiality of gases or liquid losses during combustion and mixing of gases inside the cylinder. Similarly, another finding is that by increasing the rpm, the exergy-energy of gases or liquid decreases by heat transfer and it also increases the irreversibility as well as the incompleteness of combustion. In this study it is also found that the cylinder temperature made by propane is maximum than octane and propanol. 

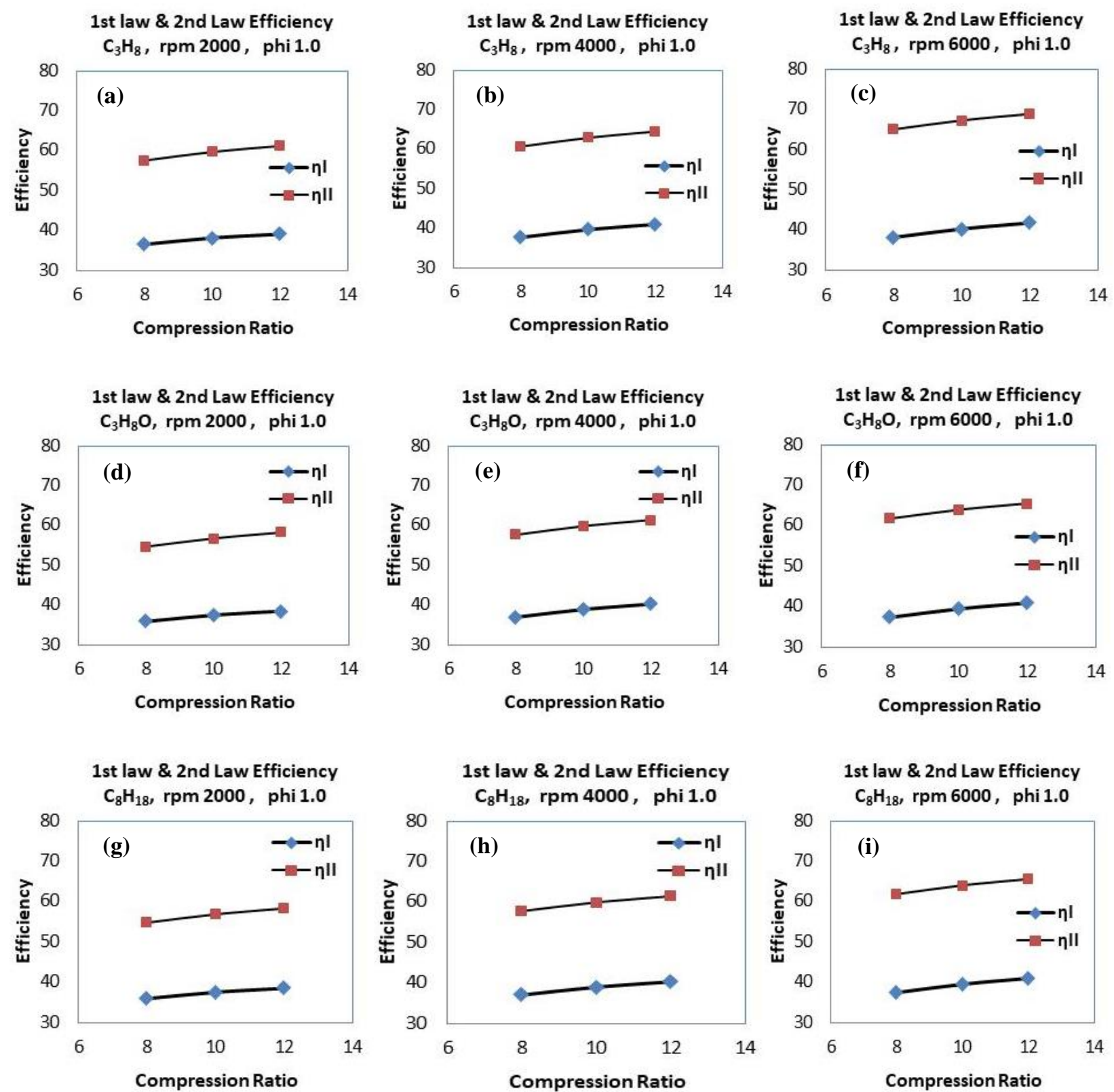

Figure 2: 1st law and 2nd law efficiency of Propane, Propanol, and Octane at different rpm and compression ratios, (a) to (i)
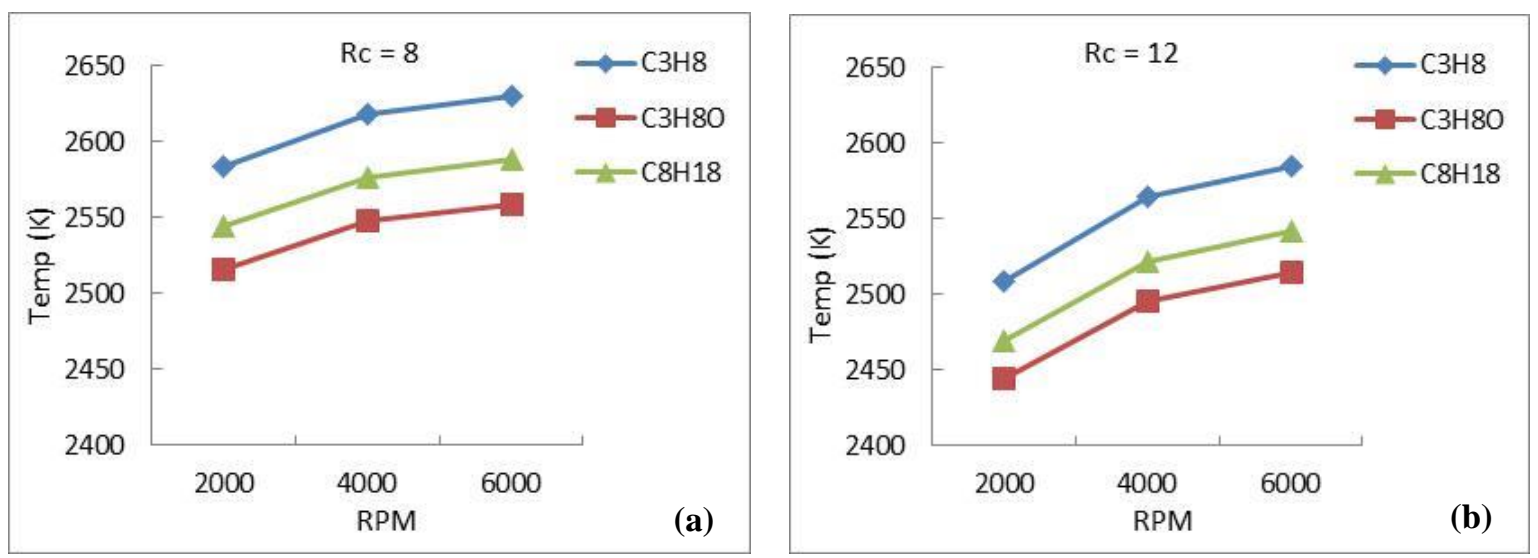

Figure 3: Comparison of maximum inside cylinder temperature for propane, propanol and octane at different rpm and compression ratio (considering stoichiometric mixture), (a) $\mathrm{Rc}=8$, and (b) $\mathrm{Rc}=12$ 


\section{CONCLUSIONS}

Energy and exergy analysis of SI engine are the important thermodynamic tools for finding better energy distribution. Irreversible process reduces the exergy of a system and leads to the inefficiency of the system. It is because of mainly for combustion process. The exhaust gas and heat transfer are also causing for exergy losses but in decreasing order. It is found that energy and exergy analysis together give a better and more accurate answer for the comparison of different fuels. However, the specific conclusions from the present study are:

a. At $2000 \mathrm{rpm}, 35.88$ to $36.56 \%$ of energy contained with fuel is converted to useful work, and the figure changes to 37.34 to $38.11 \%$ in case of $6000 \mathrm{rpm}$ at compression ratio of 8 .

b. Energy loss is found due to heat transfer from 15.32 to $16.01 \%$ and 9.74 to $10.20 \%$ at 2000 and 6000 rpm, respectively. However, associated exergy losses are found as 12.63 to $13.37 \%$ and 8.04 to $8.53 \%$ at 2000 and $6000 \mathrm{rpm}$, respectively at compression ratio of 8 .

c. Energy loss with exhaust is found as 34.01 to $35.08 \%$ and 36.63 to $37.79 \%$ at 2000 and $6000 \mathrm{rpm}$, respectively. Consecutively, exergy loss with exhaust is 16.95 to $17.82 \%$ and 18.81 to $19.79 \%$ at 2000 and $6000 \mathrm{rpm}$, respectively at compression ratio of 8 .

d. Energy loss due to friction is found as 3.54 to $3.66 \%$ and 8.89 to $9.2 \%$ at 2000 and $6000 \mathrm{rpm}$, respectively, at compression ratio of 8. Exergy losses with friction are found nearly as the same value as energy losses. Similarly, exergy contained with fuel is destroyed due to irreversibility as 29.18 to $31.87 \%$ and 25.07 to $27.94 \%$ at 2000 and 6000 rpm, respectively, at compression ratio of 8 .

The outcomes of present study provide the significance of energy-exergy based analyses to identify the potentiality of individual fuel and the sources of work potential losses in different process in the spark ignition engine.

\section{NOMENCLATURES}

$E X_{c h} \quad$ Chemical Exergy $(\mathrm{kJ} / \mathrm{kg}$-mix)

$E X_{Q} \quad$ Exergy associated with heat transfer (kJ/kg-mix)

$E X_{t m} \quad$ Thermomechanical Exergy (kJ/kg-mix)

$\left(\frac{F}{A}\right)_{S} \quad$ Stoicchiometric fuel-air ratio

$E X_{\text {fuel }} \quad$ Fuel Exergy (kJ/kg-mix)

$E X_{w} \quad$ Exergy associated with work interaction $(\mathrm{kJ} / \mathrm{kg}-\mathrm{mix})$

$y_{s} \quad$ Fuel mass fraction in stoichiometric mixture

$R_{c} \quad$ Compression Ratio

$N \quad$ Engine Speed, rpm

$\Delta g \quad$ Change of Gibbs energy (kJ/kg-mix)

$\mu_{i, 0} \quad$ Chemical potential restricted equilibrium with environment

$\mu_{i, 00} \quad$ Chemical potential unrestricted equilibrium with environment

$T_{w} \quad$ Cylinder wall temperature

$L_{c} \quad$ Connecting rod length

$L_{s} \quad$ Stroke length

$f \quad$ Residual gas fraction

$V_{D} \quad$ Displacement volume

I Total Irreversibility

\section{ACKNOWLEDGEMENTS}

The author would like to express his gratitude to the Bangladesh Military Academy (BMA), Bhatiary, Bangladesh. The author is also thankful to the editors and anonymous reviewers for providing insightful suggestions and comments to improve the manuscript.

\section{REFERENCES}

Ferguson, C. R., \& Kirkpatrick, A. T. (2001). Internal Combustion Engines: Applied Thermosciences. John Wiley $\&$ Sons.

Heywood, J. B. (1988). Internal Combustion Engine Fundamentals. McGraw-Hill.

Moran, M. J., \& Shapiro, H. N. (2000). Fundamentals of Engineering Thermodynamics. John Wiley \& Sons, New York.Bishop I. N. (1964). Effect of Design Variables on Friction and Economy. Society of Automotive Engineering (SAE), 334-379.

Eduardo, A. M., \& Fernando, A. (2017). Thermodynamic Properties of Propanol and Butanol as Oxygenate Additives to Biofuels. InTech Journal, 363-389.

Hakan, Ö., \& Abdülvahap, Ç. (2018). Comparative exergy analysis of oxygenated fuel additives in a spark-ignition (SI) engine. International Journal of Automotive Engineering and Technologies, 7(3), 124-133.

Juan, E. T., José, I. H., Sebastián, O., Luis, F. Q., \& José, E. N. (2018). The Effect of using Ethanol-Gasoline Blends on the Mechanical, Energy and Environmental Performance of InUse Vehicles. Energies, 11, 1-17.

Kumar, D., Singh, A., \& Sarma, A. K. (2015). Energy and Exergy Analysis of CI Engine for Karanja Biodiesel. International Conference on Advances in Energy Research (ICAER).

Kuntesh, M., Ashish, J. M., \& Dipak, G. (2017). Energy and Exergy Analysis on Si Engine by Blend of Ethanol with Petrol. International Journal of Advanced Engineering Research and Science, 4 (4), 49 - 61.

Mizanuzzaman, M. (2012). Effect of bore stroke ratios on overall friction model of SI engine. MIST Journal of Science and Technology, 1, 71-86.

Mizanuzzaman, M. (2013). Advantages of roller follower for different bore stroke ratios and effects on overall friction of SI engine. MIST Journal of Science and Technology, 2, 817.

Mizanuzzaman, M. (2017). Energy and Exergy Based Analysis of SI Engines Using Methane, Methanol and Octane. MIST Journal of Science and Technology, 5, 102-111.

Mizanuzzaman, M. (2018). Thermodynamic Analysis of Spark Ignition Engine Using Ethane, Ethanol and Octane. BUP Journal, 6, 99-111.

Rakopoulos, C. D. (1993). Evaluation of a spark ignition engine cycle using first and second law analysis techniques. Energy Conversion and Management, 34(12), 1299-1314.

Rakopoulos, C. D. \& Giakoumis, E. G. (2006). Second law analyses applied to internal combustion engines operation. Progress in Energy and Combustion science, 32, 2-47.

Sezer, I., Altin, I., \& Bilgin, A. (2009). Exergetic analysis of using oxygenated fuels in spark-ignition (SI) engines. Energy \& Fuels, 23(4), 1801-1807.

Sezer, I., Altin, I., \& Bilgin, A. (2008). Exergy analysis of SI engines. International Journal of Exergy (IJEX), 5(2), 204217.

Shirazi, S. A., Foust, T. D., \& Reardon, K. F. (2020). Identification of Promising Alternative Mono-Alcohol Fuel Blend Components for Spark Ignition Engines. Energies,13, 1-16. 
Simeon, I., \& Kiril, H. (2012). Analysis of Engine Speed Effects on the Four Stroke GDI Engine Performance. Proceeding in Manufacturing System, 7(4), 229-234.

Haq, M. Z., \& Morshed, A. (2013, July 29 - August 1). Energy and Exergy based analyses of a multy-fuelled SI engine.
Proceedings of the ASME 2013 Power Conference, Boston, Massachusetts, USA. (Paper No. Power 2013-98279, ASME). 